LINGUA, Vol. 15, No. 2, September 2018

p ISSN: 1979 9411; e ISSN: 2442 238X

Http://lingua.pusatbahasa.or.id; Email:presslingua@gmail.com

Center of Language and Culture Studies, Surakarta, Indonesia

Paskalis, Bossy \& Hasanah, Nurul Hana. 2018. Ketepatan dan Variasi Penggunaan Pelengkap Arah Bahasa Mandarin dalam Karangan Pembelajar.

Lingua (2018), 15(2): 53 70. DOI: 10.30957/lingua.v15i2.477

\title{
KETEPATAN DAN VARIASI PENGGUNAAN PELENGKAP ARAH BAHASA MANDARIN DALAM KARANGAN PEMBELAJAR
}

\author{
Bossy Paskalis $^{1}$ \& Hana Nurul Hasanah ${ }^{2}$ \\ Program Studi Cina, Fakultas Ilmu Pengetahuan Budaya \\ Universitas Indonesia \\ Kampus UI, Depok, Jawa Barat \\ Email: ${ }^{1}$ bossy.paskalis@ui.ac.id, ${ }^{2}$ hana.nh@ui.ac.id
}

\begin{abstract}
This research aims at describing the correct use of directional complements and elaborating the diversity and meanings of compound directional complement (CDC) used in Mandarin learners' interlanguage. This research is a case study on the essay of Universitas Indonesia Chinese Study Program students. Results were obtained through qualitative data analysis method supported by simple calculation. Learners' accuracy was reflected in identifying the direction of action, ordering the constituents in a sentence with directional complement, and selecting the motion verb. Meanwhile, inaccuracy appeared in four categories: misselection, misordering, overinclusion, and blends. On the other hand, the use of directional complements with literal meaning was very diverse, but not so for the metaphorical ones. Although the frequency of the metaphorical use of CDC was higher than the literal ones, there was a lack of the variation in the type of CDC used by the learners.
\end{abstract}

Keywords: Mandarin directional complement, foreign language learning, learners' essay, accuracy.

DOI: $10.30957 /$ lingua.v15i2.477

\section{PENDAHULUAN}

Berdasarkan makna dan strukturnya, pelengkap Bahasa Mandarin terdiri dari 7 macam, antara lain: pelengkap hasil, pelengkap arah, pelengkap kemungkinan (lihat Liu, Pan, dan Gu, 2003:534). Dari 7 macam ini, pelengkap arah memiliki frekuensi pemakaian paling tinggi daripada pelengkap lainnya, yakni 6\% lebih tinggi daripada pelengkap hasil dan sekitar 25-30\% lebih tinggi daripada pelengkap lainnya (lihat Zhao dalam Li, 2016:885-886). Dengan demikian, pelengkap arah akan sering dijumpai dalam peristiwa komunikasi berbahasa Mandarin sehingga penting bagi pembelajar untuk dapat menguasainya dengan baik.

Bentuk generik dari pelengkap arah berupa penambahan verba lai/qu 'datang/pergi' di belakang verba gerak. Penambahan lai/qu bertujuan untuk menginformasikan arah dari gerakan yang dibicarakan. Arah ini ditentukan berdasarkan perspektif pembicara. Sebuah gerak pada hakikatnya merupakan peralihan posisi dari 
LINGUA, Vol. 15, No. 2, September 2018

p ISSN: 1979 9411; e ISSN: 2442 238X

Http://lingua.pusatbahasa.or.id; Email:presslingua@gmail.com

Center of Language and Culture Studies, Surakarta, Indonesia

Paskalis, Bossy \& Hasanah, Nurul Hana. 2018. Ketepatan dan Variasi Penggunaan Pelengkap Arah Bahasa Mandarin dalam Karangan Pembelajar.

Lingua (2018), 15(2): 53 70. DOI: 10.30957/lingua.v15i2.477.

titik awal ke titik akhir; (posisi) asal ke tujuan (Hui 2011:123). Dengan demikian, untuk menyatakan arah melalui pelengkap ini pembelajar perlu mengidentifikasi titik awal, titik akhir, dan titik acuan. ${ }^{1}$

Verba gerak Bahasa Mandarin dapat diperluas dari ranah konkret ke ranah abstrak. Penambahan lai/qu di belakangnya menghasilkan konstruksi pelengkap arah bermakna kiasan/metafora. Pelengkap arah bermakna kiasan merupakan salah satu bentuk dari pelengkap arah majemuk. ${ }^{2}$ Makna perluasan atau kiasan dari verba gerak tetap berkaitan dengan makna aslinya (Hui, 2011:120). Di dalam penggunaan pelengkap arah bermakna kiasan tetap terdapat titik awal dan titik akhir atau tempat asal dan tujuan. Akan tetapi, dapat diprediksikan tidak mudah bagi pembelajar asing untuk memahami konsep metafora dalam pelengkap arah karena konsep itu tidak diperoleh dari pengalaman sendiri.

Dalam literatur pembelajaran Bahasa Mandarin, pelengkap arah disebut sebagai pelengkap yang makna gramatikalnya rumit, penggunaannya terikat dengan perspektif pembicara, dan sulit dikuasai pembelajar (Liu, Pan, dan Gu, 2003; Li, 2016). Dikarenakan penggunaannya cukup rumit, penelitian terdahulu mengenai pelengkap arah banyak menyoroti sisi teoretisnya dan belum banyak penelitian mengenai penggunaan pelengkap arah Bahasa Mandarin dalam kalimat pembelajar.

Li (2016) menyelidiki faktor-faktor yang berperan dalam penguasaan pelengkap arah Bahasa Mandarin terhadap pembelajar dengan bahasa pertama (B1) yang berbedabeda (Korea, Jepang, Inggris). Berdasarkan hasil kuesioner (bentuk tes) yang dirancang untuk menilai kemampuan penggunaan pelengkap arah, disimpulkan bahwa faktor yang mempengaruhi penguasaan pelengkap arah oleh pembelajar adalah bahasa pertama dan konsep metafora dari verba gerak.

Selain penelitian di atas, penelitian terhadap pembelajar dengan latar belakang B1 Bahasa Indonesia pernah dilakukan oleh Sijabat (2012). Fokus penelitiannya mengenai bentuk kesalahan dan faktor penyebab kesalahan dalam penggunaan pelengkap arah sederhana oleh mahasiswa semester IV Program Studi Sastra Cina Universitas Sumatera Utara. Bentuk kesalahan yang dilakukan oleh mereka adalah kesalahan dalam penempatan pelengkap arah dan penambahan lai atau $q u$ untuk kalimat yang tidak memerlukan pelengkap arah. Hal ini disebabkan karena pemahaman mahasiswa terhadap konsep lai dan qu sebagai pelengkap arah masih kurang baik.

Dua penelitian di atas tidak menggunakan data autentik pembelajar dan belum mengkaji performa pembelajar secara utuh. Performa adalah kemampuan untuk memahami atau memproduksi bahasa (Cook, 2001:81). Analisis performa tidak hanya mencakup kesalahan-kesalahan pembelajar saja, tetapi juga aspek-aspek positif atau kepatuhan tata bahasa dalam performa pembelajar. Pada dasarnya, penggunaan bahasa pembelajar yang salah dan yang tepat sebagai data analisis dapat digunakan untuk menginvestigasi hasil pembelajaran dan proses penguasaan bahasa sasaran.

\footnotetext{
${ }^{1}$ Titik acuan disebut juga sebagai titik tumpu (lizú di $n$ 立足点) oleh Liu, Pan, dan Gu (2003: 547).

${ }^{2}$ Jenis-jenis pelengkap arah akan dijelaskan pada Subbab 2.
} 
LINGUA, Vol. 15, No. 2, September 2018

p ISSN: 1979 9411; e ISSN: 2442 238X

Http://lingua.pusatbahasa.or.id; Email:presslingua@gmail.com

Center of Language and Culture Studies, Surakarta, Indonesia

Paskalis, Bossy \& Hasanah, Nurul Hana. 2018. Ketepatan dan Variasi Penggunaan Pelengkap Arah Bahasa Mandarin dalam Karangan Pembelajar.

Lingua (2018), 15(2): 53 70. DOI: 10.30957/lingua.v15i2.477

Dalam bahasa pembelajar terdapat sistem yang menjadi perantara antara bahasa asli dan bahasa sasaran yang disebut dengan antarbahasa (Brown, 2007:281). Antarbahasa bukan hanya merupakan bukti pembelajaran bahasa, melainkan hasil kompleks dari proses kognitif internal yang terjadi selama proses pemerolehan bahasa kedua (Luna, 2010:61). Analisis antarbahasa dapat dilakukan dengan mengkaji wicara dan tulisan pembelajar (bahasa pembelajar). Dua pendekatan yang umumnya diterapkan dalam menganalisis antarbahasa adalah "kesalahan" dan "performa".

Ruang lingkup penelitian ini mencakup keseluruhan performa pembelajar; menganalisis ketepatan dan ketidaktepatan penggunaan pelengkap arah dalam karangan mahasiswa. Penelitian ini bertujuan untuk mendeskripsikan penguasaan salah satu unsur gramatika Bahasa Mandarin dalam antarbahasa pembelajar Bahasa Mandarin berlatar belakang B1 Bahasa Indonesia. Informasi mengenai dalam kalimat seperti apa pembelajar bisa melakukan kesalahan serta apa bentuk kesalahannya, dan di mana letak ketepatan mereka, dapat digunakan sebagai referensi bagi pengajar untuk merancang strategi pengajaran pelengkap arah di kelas, khususnya untuk pembelajar Indonesia tingkat perguruan tinggi.

Berdasarkan pertimbangan di atas, pertanyaan yang diangkat dalam penelitian ini adalah:

1) Seperti apa letak ketepatan dan ketidaktepatan penggunaan pelengkap arah dalam karangan mahasiswa?

2) Terkait dengan pelengkap arah majemuk, jenis pelengkap arah majemuk manakah yang paling banyak digunakan oleh mahasiswa dan makna kiasan apa saja yang telah digunakan mahasiswa?

Ketidaktepatan dalam penggunaan pelengkap arah dengan makna harfiah (penunjuk arah) diasumsikan terletak pada hubungan arah gerak dengan pembicara. Sementara itu, ketidaktepatan dalam penggunaan pelengkap arah dengan makna kiasan terdapat pada pemilihan verba gerak, terkait dengan makna kiasan yang dapat dinyatakan verba gerak tersebut. Karena kompleksitas pelengkap arah bermakna harfiah berbeda dengan yang bermakna kiasan, hal ini diasumsikan akan mempengaruhi frekuensi penggunaan dan urutan penguasaan. Penggunaan pelengkap arah bermakna harfiah diasumsikan lebih tinggi dan lebih mudah dikuasai daripada yang bermakna kiasan.

Pada subbab selanjutnya akan dijelaskan secara singkat mengenai batasan, ciriciri, dan jenis pelengkap arah Bahasa Mandarin. Pemaparan mengenai sumber data, subjek penelitian, metode dan tahap analisis data terdapat di dalam subbab Metode. Pada subbab Hasil dan Bahasan, penulis menunjukkan frekuensi ketepatan dan ketidaktepatan dari penggunaan tiap jenis pelengkap arah serta mendeskripsikan letak ketepatan dan ketidaktepatannya. Terakhir, penulis memberikan kesimpulan dari hasil dan temuan penelitian ini dalam subbab Simpulan.

\section{PELENGKAP ARAH BAHASA MANDARIN}

Pelengkap arah Bahasa Mandarin merupakan unsur tambahan yang berfungsi untuk menginformasikan arah suatu perbuatan yang bergerak dari titik awal ke titik 
akhir dan dikaitkan dengan posisi pembicara. Unsur tambahan ini adalah verba gerak lái 来 'datang' atau qù 去 'pergi'. Lái digunakan apabila arah perbuatan mendekati pembicara [posisi pembicara di titik akhir atau sama dengan posisi tujuan], sedangkan qù digunakan apabila arah perbuatan menjauhi pembicara [posisi pembicara di titik awal atau sama dengan posisi asal] (Liu, Pan, dan Gu, 2003; Li dan Cheng, 2008; Roose, 2010). Sementara itu, perbuatan yang dilengkapinya terbatas pada 7 verba gerak sebagai berikut: shàng 上 'naik', xià 下 'turun', jìn 进 'masuk', chū 出 'keluar', huí 回 'kembali', guò 过 'lewat', dan $q$ 起 'bangkit' (Peyraube, 2006:125). Lai/qu yang ditambahkan di belakang verba di atas berfungsi sebagai pelengkap arah sederhana/ji ndān qūxiàng $b$ y /simple directional complement (selanjutnya disebut SDC). ${ }^{3}$ Dengan kata lain, lai/qu baru dapat berfungsi sebagai pelengkap apabila didahului oleh verba yang pada hakikatnya menunjukkan arah gerak dari perbuatan yang dilakukan. Misalnya, verba gerak shang 'naik'; arah perbuatan "naik"-tanpa ada pilihan lain—arah atas; verba gerak xia 'turun' arah perbuatan "turun" adalah arah bawah, dan sebagainya.

Untuk memberikan informasi arah selain dari perbuatan-perbuatan yang dinyatakan melalui 7 verba di atas, lai/qu tidak bisa "bertindak" sendiri, melainkan harus bergabung dengan salah satu dari 7 verba gerak di atas, dengan pengecualian bentuk * 起去 qiqu (Li dan Cheng, 2008). Bentuk gabungan ini disebut pelengkap arah majemuk/fühé qūxiàng $b$ y /compound directional complement (selanjutnya disebut CDC). CDC terdiri dari 13 jenis sebagai berikut: (1) 上来 shanglai, (2) 上去 shangqu, (3) 下来 xialai, (4) 下去 xiaqu, (5) 进来 jinlai, (6) 进去 jinqu, (7) 出来 chulai, (8) 出去 chuqu, (9) 回来 huilai, (10) 回去 huiqu, (11) 过来 guolai, (12) 过去 guoqu, dan (13) 起 来 qilai.

CDC ditambahkan di belakang salah satu dari dua tipe verba berikut ini (Peyraube, 2006:125; Dippner, 2010:11):

(i) verba yang menunjukkan cara sebuah gerakan/perbuatan dilakukan subjek, misalnya: $z u$ 走 'jalan', $p o$ 跑 'lari', $f \bar{e} i$ 飞 'terbang', $g$ 滚 'berguling';

(ii) verba transitif yang menunjukkan perubahan tempat dari nomina yang mengikutinya, misalnya: bān 搬 'pindah', ná 拿 'ambil; bawa', tū 推 'dorong', $d$ 打 'pukul'.

Berdasarkan penjelasan di atas, terlihat ada dua macam pelengkap arah Bahasa Mandarin, yaitu SDC dan CDC. Pola dasarnya tampak pada Tabel 1.

Tabel 1. Pola dasar SDC dan CDC

\begin{tabular}{|c|c|c|}
\hline Perspektif & SDC & CDC \\
\hline Mendekati pembicara & Verba gerak $+l a i$ 来 & Verba (i)/(ii) + Verba gerak $+l a i$ 来 \\
\hline Menjauhi pembicara & Verba gerak $+q u$ 去 & Verba (i)/(ii) + Verba gerak $+q u$ 去 \\
\hline
\end{tabular}

\footnotetext{
${ }^{3}$ Singkatan ini mengacu kepada istilah pelengkap ini dalam Bahasa Inggris yang lebih umum ditemukan dalam artikel ilmiah sejenis dan sejalan dengan penyingkatan yang ditemukan dalam Li (2016).
} 
LINGUA, Vol. 15, No. 2, September 2018

p ISSN: 1979 9411; e ISSN: 2442 238X

Http://lingua.pusatbahasa.or.id; Email:presslingua@gmail.com

Center of Language and Culture Studies, Surakarta, Indonesia

Paskalis, Bossy \& Hasanah, Nurul Hana. 2018. Ketepatan dan Variasi Penggunaan Pelengkap Arah Bahasa Mandarin dalam Karangan Pembelajar.

Lingua (2018), 15(2): 53 70. DOI: 10.30957/lingua.v15i2.477

Dengan demikian, sebuah kalimat Bahasa Mandarin dimungkinkan untuk bukan sekadar menyatakan perbuatan yang dilakukan subjek. Melalui penggunaan SDC, arah dari perbuatan yang dibicarakan (mendekati atau menjauhi pembicara) pun tersampaikan dan melalui penggunaan CDC dapat ditambah dengan informasi tentang arah gerak dari perbuatan yang dibicarakan (Roose, 2010; Cakradiwati dan Hasanah, 2017).

Selain dapat mendampingi salah satu dari dua tipe verba di atas, CDC juga dapat mendampingi adjektiva (Liu, Pan, dan Gu, 2003:546). Penggunaan seperti ini akan memunculkan makna kiasan dari CDC. Akan tetapi, hal ini bukan berarti makna kiasan dari CDC hanya muncul pada waktu mendampingi adjektiva. Penggunaan CDC di belakang salah satu tipe verba di atas juga bisa memunculkan makna kiasan/metafora.

Dilihat dari susunannya di dalam kalimat, konstituen lain (bila ada) diletakkan sebelum lai/qu. Keterangan tempat, objek langsung dari sebuah perbuatan, partikel aspektual le, guo, atau zhe harus diletakkan sebelum lai/qu atau di antara verba gerak dengan lai/qu (Li dan Cheng, 2008; CTCFL, ${ }^{4}$ nd.). Akan tetapi, le sebagai partikel fatis diletakkan di belakang lai/qu.

\section{METODE}

Penelitian ini berupa studi kasus karangan mahasiswa peserta mata kuliah Bahasa Cina V dan Bahasa Cina VI. Beberapa aspek yang diukur dari karangan pembelajar mencakup kelogisan berpikir yang tertuang dalam alur dan isi cerita, penggunaan alatalat kohesi serta unsur-unsur gramatika dalam Bahasa Mandarin. Oleh karena itu, mudah ditemukan penggunaan pelengkap dalam karangan mereka, tak terkecuali pelengkap arah.

Metode analisis data yang digunakan merupakan metode kualitatif yang ditunjang dengan penghitungan sederhana. Analisis kualitatif digunakan untuk menjelaskan letak ketepatan penggunaan pelengkap arah dalam kalimat pembelajar dan makna kiasan dari CDC, sedangkan analisis kuantitatif digunakan untuk menghitung frekuensi ketepatan dan ketidaktepatan serta keberagaman pelengkap arah yang ditemukan dalam kalimat pembelajar.

Subjek penelitian ini adalah mahasiswa Program Studi Cina Universitas Indonesia peserta mata kuliah Bahasa Cina (BC) V dan BC VI tahun ajar 2014/2015 sampai dengan 2016/2017 yang memiliki prestasi akademik yang beragam (rentang nilai A-C) dan merupakan mahasiswa dari penulis kedua. Sementara itu, data yang digunakan dalam penelitian ini berupa kalimat-kalimat dari karangan mereka. Karangan dipilih secara acak meliputi hasil latihan dan tes. Jumlah keseluruhannya adalah 113 karangan tetapi hanya 58 karangan yang di dalamnya terdapat kalimat-kalimat berpelengkap arah. Di dalam 58 karangan tersebut, terdapat 133 kalimat berpelengkap arah. Namun, setelah dicek kembali keakuratan penggunaan kosakata dan unsur gramatika selain pelengkap arah, ada 50 kalimat yang tidak dapat diikutsertakan dalam penelitian ini. Dengan demikian, hanya 83 kalimat yang dapat digunakan sebagai data. Pengecekan keakuratan

\footnotetext{
${ }^{4}$ CTCFL: Elementary Chinese revision notes and exercises, http://www.ctcfl.ox.ac.uk/Grammar\%20 exercises/DC.htm).
} 
kalimat-kalimat pembelajar dilakukan oleh seorang narasumber yang merupakan pengajar siswa asing di Chinese Language Center, National Chengchi University, Taiwan.

Analisis data, pertama-tama dilakukan dengan mengelompokkan kalimat berpelengkap arah yang penggunaannya tepat dan yang tidak tepat, lalu dilanjutkan dengan menghitung frekuensinya. Selanjutnya, mengidentifikasi letak ketepatan dan ketidaktepatan penggunaan pelengkap arah di dalam tiap kalimat dengan mengacu ke teori pelengkap arah dari Liu, Pan, dan Gu (2003), Li dan Cheng (2008), Dippner (2010) dan dua buku referensi (Hanyu Jiaocheng Di'erce, 2012 dan Modern Chinese, 1981). Langkah berikutnya adalah mengelompokkan kalimat-kalimat yang tidak tepat berdasarkan tipe kesalahannya dengan mengacu ke Taksonomi Modifikasi Bahasa Sasaran (James, 1998:106-111). Terakhir, menghitung kemunculan jenis-jenis CDC yang digunakan pembelajar dan mengidentifikasi makna kiasannya.

\section{HASIL DAN BAHASAN}

Dalam 83 kalimat yang dianalisis, ditemukan 90 penggunaan pelengkap arah; 10 penggunaan SDC, 37 penggunaan CDC dengan makna arah, dan 43 penggunaan CDC dengan makna kiasan. Sebagian besar penggunaan SDC sudah tepat, ketidaktepatan hanya muncul 2 kali. Di sisi lain, tingkat ketepatan penggunaan CDC juga tinggi. Secara umum, CDC qilai dengan makna kiasan merupakan jenis pelengkap arah dengan tingkat ketepatan tertinggi. Dapat dikatakan bagi subjek penelitian ini, qilai merupakan jenis CDC yang mudah dikuasai. Hal ini berbeda dengan hasil penelitian $\mathrm{Li}$ yang menyatakan pelengkap arah dengan verba gerak hui dan jin (keduanya tidak memiliki pemakaian kiasan) sebagai bentuk yang mudah dikuasai oleh pembelajar dengan B1 Bahasa Korea, Bahasa Jepang, dan Bahasa Inggris (Li, 2016:893). Persentase ketepatan dan ketidaktepatan penggunaan pelengkap arah secara keseluruhan dapat dilihat dalam diagram 1.

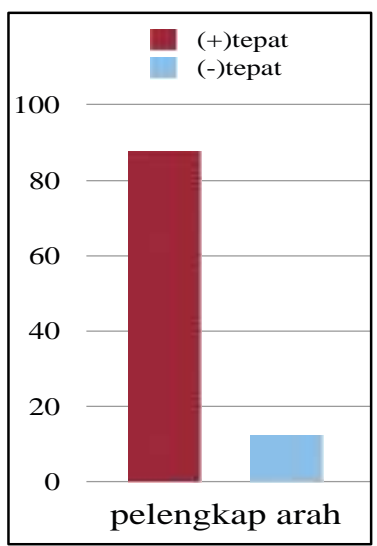

Diagram 1. Tingkat ketepatan penggunaan pelengkap arah 
LINGUA, Vol. 15, No. 2, September 2018

p ISSN: 1979 9411; e ISSN: 2442 238X

Http://lingua.pusatbahasa.or.id; Email:presslingua@gmail.com

Center of Language and Culture Studies, Surakarta, Indonesia

Paskalis, Bossy \& Hasanah, Nurul Hana. 2018. Ketepatan dan Variasi Penggunaan Pelengkap Arah Bahasa Mandarin dalam Karangan Pembelajar.

Lingua (2018), 15(2): 53 70. DOI: 10.30957/lingua.v15i2.477

\subsection{Letak Ketepatan dan Ketidaktepan Pelengkap Arah dalam Kalimat Pembelajar}

Pelengkap arah yang ditemukan dalam karangan pembelajar muncul dalam beragam jenis kalimat, tunggal maupun majemuk, yang di dalamnya tidak hanya terdiri dari konstituen subjek dan predikat. Tingkat ketepatan yang tinggi menunjukkan bahwa pembelajar sudah memahami susunan kalimat berpelengkap arah dalam berbagai bentuk.

(1) 三个 星期 左右, 面试 结果 出 来 了。5
Sān ge xīngqī zu yòu, miànshì jiégu dhū lai le.
'Sekitar tiga minggu kemudian, hasil wawancara keluar.'

Di dalam kalimat (1) terdapat penggunaan SDC lai . Kalimat ini menggambarkan objek "hasil wawancara (miànshì jiégu )" telah keluar atau dipublikasikan (ditandai dengan penggunaan partikel le). Objek pada kalimat (1) dikedepankan sehingga pembelajar sudah tepat menempatkan le di belakang SDC lai.

(2) 我 急忙 走进妈妈 的 卧室 去。

$W$ jímáng zòujin māma de wòshì qu.

'Saya bergegas masuk ke kamar ibu.'

Kalimat (2) menunjukkan penggunaan CDC jinqu yang disisipi oleh keterangan tempat. "Kamar ibunya (māma de wòshì)" merupakan keterangan tempat pada kalimat (2). Berdasarkan susunan yang baku, apabila terdapat keterangan tempat, CDC tidak dapat berdampingan, di antaranya disisipi keterangan tempat (Liu, Pan, dan Gu, 2003; Li dan Cheng, 2008; Yang, 2013). Dengan demikian pembelajar sudah tepat meletakkan "māma de wòshi” di antara verba gerak (jin 'masuk') dengan verba penunjuk arah (qu).

Selain sudah dapat menyusun kalimat berpelengkap arah yang sesuai kaidah, pembelajar juga sudah mampu menentukan hubungan antara titik acuan dengan arah perbuatan. Hal ini tercermin pada kalimat (2) di atas. Kalimat (2) menggambarkan subjek yang terburu-buru berjalan memasuki kamar ibunya. Titik awal subjek adalah luar kamar ibunya, titik akhirnya adalah kamar ibunya, sedangkan titik acuannya adalah subjek itu sendiri $(w)$. Perbuatan berjalan memasuki kamar ibu yang dilakukan oleh $w$ menunjukkan gerak yang menjauhi titik awal yang sekaligus merupakan titik acuan. Dalam hal ini pembelajar telah tepat memilih $q u$ yang berfungsi untuk menunjukkan arah perbuatan yang menjauhi titik acuan.

Letak ketepatan selanjutnya dilihat dari segi pemilihan verba gerak dalam CDC. Verba gerak merupakan salah satu konstituen CDC dan terletak sebelum lai/qu.

(3) 回 家的 时候, 妈妈一看到 我 就 不禁流下了眼泪 来。 Huí jiā de shíhòu, māma yí kàndao w jiù bùjīn liúxia le y nlèi laí.

\footnotetext{
${ }^{5}$ Catatan: dalam artikel ini predikat kalimat ditebalkan, rangkaian pelengkap arah digaris bawah, sedangkan bagian dari kalimat berpelengkap arah yang tidak tepat diberikan tanda garis bawah ganda.
} 
'Ketika pulang ke rumah, begitu melihat saya, air mata ibu menetes tak tertahankan.'

Kalimat (3) menggambarkan subjek "ibu (māma)" yang tidak dapat menahan air matanya mengalir setelah melihat "saya $(w)$ " pulang ke rumah. Air mata yang mengalir menunjukkan gerakan menuju bawah (dari kelopak mata turun ke pipi). Dalam hal ini pembelajar telah tepat memilih verba gerak xia 'turun' yang berfungsi untuk menunjukkan arah perbuatan dari tempat tinggi menuju tempat rendah.

Ketepatan pembelajar dalam pemilihan verba gerak tidak terbatas pada CDC bermakna arah, tetapi juga tercermin dalam penggunaan CDC bermakna kiasan.

(4) 他 终于 要 把 英语 学下去。

Tã zhōngyú yào b Yīngy xué xiaqu.

'Dia akhirnya mau terus belajar bahasa Inggris.'

Kalimat (4) menggambarkan subjek yang pada akhirnya terus melanjutkan belajar Bahasa Inggris. Di dalam karangan diceritakan bahwa "dia $(t \bar{a})$ " telah mempelajari Bahasa Inggris tetapi kemampuan berbicaranya tidak terlalu baik sehingga memutuskan untuk melanjutkan belajar Bahasa Inggris. Perbuatan melanjutkan suatu aktivitas yang telah dilakukan sebelumnya menunjukkan sebuah keberlanjutan. Arah gerak menurun (xia) diumpamakan sebagai "alur maju", sedangkan perbuatan yang terus akan dilakukan di masa yang akan datang diumpamakan meninggalkan (pergi ' $q u$ ') titik acuan "sekarang" (Dippner, 2010:44). Dengan demikian, pembelajar telah memilih verba gerak yang tepat untuk kalimat (4). ${ }^{6}$

Di sisi lain, juga ditemukan beberapa kalimat pembelajar yang tidak tepat. Ketidaktepatan penggunaan SDC ataupun CDC yang ditemukan dalam kalimat pembelajar terletak pada:

(i) pemilihan lai/qu atau verba gerak,

(ii) susunan antara pelengkap arah dengan unsur lain di dalam kalimat,

(iii) penyamarataan aturan susunan kalimat,

(iv) pemilihan verba gerak dan letak partikel le.

Dengan demikian, dari 5 tipe kesalahan dalam Taksonomi Modifikasi Bahasa Sasaran, misselection, misordering, omission, overinclusion, blends (James, 1998:106-111), yang muncul dalam kalimat pembelajar adalah: salah pilih, salah susun, generalisasi berlebihan, dan campuran. Tipe penghilangan (omission) yang tidak muncul dalam penelitian ini justru merupakan bentuk ketidaktepatan yang lazim ditemukan dalam kalimat pembelajar dengan latar belakang B1 Bahasa Thailand, Laos, dan Vietnam (Qi dalam Qi, Zhao, Wei, 2016).

\footnotetext{
${ }^{6}$ Penjelasan lebih lanjut mengenai penggunaan CDC dalam kalimat pembelajar dapat dilihat dalam Subbab 4.2.
} 
LINGUA, Vol. 15, No. 2, September 2018

p ISSN: 1979 9411; e ISSN: 2442 238X

Http://lingua.pusatbahasa.or.id; Email:presslingua@gmail.com

Center of Language and Culture Studies, Surakarta, Indonesia

Paskalis, Bossy \& Hasanah, Nurul Hana. 2018. Ketepatan dan Variasi Penggunaan Pelengkap Arah Bahasa Mandarin dalam Karangan Pembelajar.

Lingua (2018), 15(2): 53 70. DOI: 10.30957/lingua.v15i2.477

\section{1) Salah Pilih}

Secara garis besar, ada dua bentuk ketidaktepatan yang termasuk ke dalam tipe salah pilih, yaitu salah pilih verba penunjuk arah (lailqu) dan salah pilih verba gerak. Ketidaktepatan bentuk pertama muncul satu kali dalam penggunaan SDC dan dua kali dalam penggunaan CDC dengan makna arah. Berikut ini merupakan salah satu contohnya yang ditemukan dalam penggunaan CDC.

(5) 我看一看我的 公文包 快 掉下来了。

$W$ kànyikàn $w$ de gōngwénbāo kuài ciàoxialai le.

Di dalam karangan, tokoh "saya ( $w$ )" pada kalimat (5) digambarkan sedang mengendarai sepeda. Tas kerjanya diletakkan di atas boncengan sepeda. Ia mengendarai sepeda sambil melihat-lihat ke belakang, mengamati tas kerjanya dalam posisi semula atau tidak. Pada saat ia menengok ke arah boncengan, ia melihat tas kerjanya segera akan jatuh (diào) dari atas boncengan. Arah jatuhnya tersebut, tanpa perlu diperdebatkan tentunya mengarah ke bawah (xia), menuju ke permukaan jalan dan pada saat yang sama menjauhi titik acuan, yaitu tokoh "saya $(w)$ " yang berada di atas sepeda. Jika perbuatan menjauhi titik acuan, $q u$ akan digunakan untuk mengambarkan kondisi tersebut. Akan tetapi, dalam kalimat (5) pembelajar justru menggunakan lai yang seharusnya digunakan apabila perbuatan mendekati titik acuan. Ketidaktepatan pemilihan verba penunjuk arah pada kalimat (5) termasuk dalam tipe kesalahan salah pilih (misselection). Kalimat (5) seharusnya berbunyi:

\section{我看一看我的 公文包 快 掉下去了 \\ $W$ kàn yi kàn w de gōngwénbāo kuài diàoxiaqu le. \\ 'Saya lihat, tas kerja saya akan jatuh.'}

Penentuan arah perbuatan dengan titik acuan nampaknya menjadi kesulitan tersendiri bagi pembelajar dalam menggunakan pelengkap arah dengan makna harfiahnya (penunjuk arah). Hal serupa tidak ditemukan dalam penggunaan CDC dengan makna kiasan.

Unsur lain yang perlu dipertimbangkan dalam penggunaan CDC, adalah verba gerak. CDC ada 13 jenis dan tiap jenisnya dapat mendampingi berbagai verba. Selain itu, satu verba yang sama dapat didampingi oleh beberapa jenis CDC. Penentuan verba apa didampingi CDC yang mana tergantung dari arah gerak perbuatan. Mengenai hal ini, pembelajar belum selalu tepat mengidentifikasi arah gerak dari perbuatan yang dibicarakan ( $\mathrm{P}$ dalam kalimat). Ketidaktepatan ini muncul dalam penggunaan CDC dengan makna arah dan kiasan, misalnya:

(6) 原因是因 穿 深 色调的衣服, 而使我 看出来比较瘦。

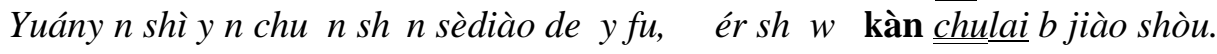


LINGUA, Vol. 15, No. 2, September 2018

p ISSN: 1979 9411; e ISSN: 2442 238X

Http://lingua.pusatbahasa.or.id; Email:presslingua@gmail.com

Center of Language and Culture Studies, Surakarta, Indonesia

Paskalis, Bossy \& Hasanah, Nurul Hana. 2018. Ketepatan dan Variasi Penggunaan Pelengkap Arah Bahasa Mandarin dalam Karangan Pembelajar.

Lingua (2018), 15(2): 53 70. DOI: 10.30957/lingua.v15i2.477.

Ketidaktepatan penggunaan CDC pada kalimat (6) berada pada anak kalimat terakhir. Predikat "terlihat (kàn)" merupakan suatu bentuk penilaian subjek "saya ( $w$ )" terhadap dirinya sendiri yang nampak agak kurus ketika mengenakan pakaian berwarna gelap. Jadi, kalimat (6) tidak bertujuan membicarakan arah gerak "keluar" (chu) dari suatu perbuatan. Apabila merujuk ke penggunaan kiasan chulai menurut Dippner (2010), tidak ditemukan fungsi chulai untuk menyatakan penilaian terhadap suatu situasi. CDC yang memiliki fungsi seperti ini adalah qilai. Dengan demikian, verba gerak yang seharusnya digunakan adalah qi. Hal ini juga didukung oleh predikat kàn yang terkait dengan panca indra (penglihat). Penggunaan qilai untuk menunjukkan asumsi atau penilaian terhadap suatu situasi dilakukan berdasarkan verba indrawi (sense verbs) yang dinyatakan dalam kalimat tersebut (Dippner, 2010:59). Selain itu, bentuk kàn qilai merupakan bentuk yang sangat umum dalam Bahasa Mandarin percakapan untuk menyatakan penilaian yang longgar atau hanya berdasarkan pengamatan personal (subjektif). Jadi, kalimat (6) seharusnya seperti kalimat berikut ini:

原因 是因穿 深 色调的衣服, 而使 我 看 起来 比较 瘦。

Yuányīn shì yīn chuān shēn sèdiào de yīfu, ér sh $w$ kànqilai b jiào shòu.

'Alasannya adalah saya terlihat lebih kurus apabila mengenakan pakaian berwarna gelap.'

\section{2) Salah Susun}

CDC tersusun atas gabungan antara verba gerak dengan lailqu. Di dalam kalimat, dua unsur ini dapat berdampingan dan bisa juga disisipi unsur lain, misalnya keterangan tempat atau objek yang mengalami perpindahan akibat perbuatan yang dilakukan. Peletakan keterangan tempat atau objek di antara verba gerak dan lai/qu pada dasarnya merupakan susunan baku dari kalimat dengan CDC. Pengecualian hanya terjadi apabila di dalam kalimat juga terdapat aspek perfektif le. Pada kondisi seperti ini objek dapat diletakkan di depan atau di belakang lai/qu (Universitas Peking, 1981:185; Yang, 2013:140).

（7）吃 完 蛋糕 后, 我妈 拿出来 照相机, 把 我们 拍下来。 Chī wán dàngāo hòu, $w$ mā ná chulai zhàoxiàngjī, $b \quad w$ men päi xialai.

Susunan kalimat (7) adalah P + v.gerak $c h u+l a i+$ O. Namun, karena kalimat (7) merupakan kalimat tanpa partikel le, susunan yang seharusnya adalah $\mathrm{P}+\mathrm{v}$.gerak chu + $\mathrm{O}+$ lai. Jadi, dapat dikatakan ketidaktepatan terletak pada susunan kalimat, yakni tempat antara lai dan objek tertukar. Kalimat (7) seharusnya seperti berikut ini:

吃 完 蛋糕 后, 我妈 拿出 照相机 来, 把我们 拍下来。

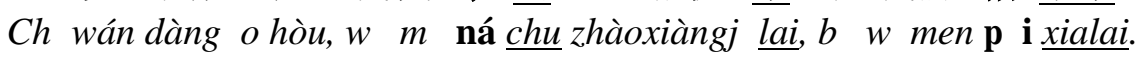

'Setelah menghabiskan kuenya, Ibu mengeluarkan kamera, lalu memotret kami.'

Berdeda dengan hasil penelitian Sijabat (2012), pada data penelitian ini penempatan keterangan tempat tidak menjadi masalah, ketidaktepatan justru muncul pada letak objek dalam kalimat berpelengkap arah. Bentuk salah susun seperti ini juga 
tidak sejalan dengan penelitian Qi yang menemukan bahwa penukaran lai/qu dengan keterangan tempat adalah tipe salah susun yang paling sering muncul dalam antarbahasa pembelajar Laos, Vietnam, dan Thailand (Qi dalam Qi, Zhao, Wei, 2016).

\section{3) Generalisasi Berlebihan}

Aturan penempatan SDC dalam kalimat pada dasarnya sederhana, yakni penambahan lai atau $q u$ di belakang predikat verbal. Akan tetapi, penyusunan kalimat dengan SDC menjadi lebih kompleks bila kalimat tersusun dari berbagai unsur selain unsur utamanya (predikat). Namun, apabila ada partikel aspektual le di dalam kalimat, aturan yang sederhana menjadi lebih kompleks dan berpotensi menimbulkan kebingungan bagi pembelajar (Roose, 2010:4). Untuk objek dengan atributif, le diletakkan di belakang $\mathrm{P}$, sedangkan objek terletak di belakang $l e(\mathrm{P}+l e+\mathrm{O}+$ lai/qu $)$ atau di belakang lai/qu $(\mathrm{P}+$ lai $q u+l e+\mathrm{O})$. Aturan ini hanya berlaku untuk kalimat berobjek. Akan tetapi, ditemukan satu kalimat pembelajar yang menerapkannya untuk kalimat dengan keterangan tempat seperti berikut ini:

(8) 母亲进了我的房间 来。 $M$ qin jìnle $w$ de fángjiān $\underline{\underline{\text { lai }}}$.

$W$ de fángjiān 'kamar saya' merupakan keterangan tempat dalam kalimat (8). Walaupun di dalam kalimat (8) terdapat le, pembelajar tidak seharusnya menyamaratakan aturan dan menempatkan $l e$ di belakang $\mathrm{P}$ sebagaimana dalam kalimat berobjek. Untuk kalimat dengan keterangan tempat yang di dalamnya juga terdapat partikel le, aturannya hanya satu, yakni: $\mathrm{P}+$ Ket. Tempat + lai $/ q u+l e$ (Universitas Peking, 1981:27). Berdasarkan aturannya, kalimat (8) seharusnya seperti kalimat berikut ini:

\section{母亲进我的房间来了。}

$M$ qin jìn $w$ de fángjiān lai le.

'Ibu masuk ke kamar saya.'

\section{4) Campuran}

Ketidaktepatan jenis ini muncul dua kali dan keduanya muncul dalam penggunaan CDC dengan makna kiasan. Salah satu contohnya adalah:

\section{(9) 妈妈 不由得 恸哭了出来。 \\ Māma bùyóude tòngkū le chulai.}

Kalimat (9) menggambarkan ibu ( $m \bar{a} m a$ ) dari tokoh "saya" yang tak tahan menahan tangis karena ditinggal suaminya (ayah dari tokoh "saya"). Di dalam karangan dikatakan bahwa ayah dari tokoh "saya" meninggal secara tiba-tiba. Mengahadapi hal ini, "Māma" tidak bisa menahan kesedihannya dan mulai menangis pilu (tòngkū). Keadaan seperti ini dapat digambarkan dengan penggunaan CDC dengan makna kiasan 
mulainya suatu perbuatan. Verba gerak "chu" tidak memiliki makna kiasan ini. Makna kiasan seperti ini terdapat dalam verba gerak “qi”. Dippner (2010), Li dan Cheng (2008) mengemukakan qilai memiliki makna kiasan yang menunjukkan dimulainya suatu perbuatan. Selain itu, karena kalimat ini menunjukkan perubahan keadaan dari tidak sedih menjadi sedih, le sebagai penanda perubahan keadaan seharusnya berada di akhir kalimat. Jika diperbaiki, kalimat (9) akan menjadi seperti ini:

\section{妈妈 不由 得 恸 哭起来了。 \\ Māma bù yóu de tòngkū qilai le. \\ 'Ibu tidak bisa menahan tangisnya.'}

\subsection{Penggunaan CDC dan Makna Kiasan}

Dalam karangan pembelajar ditemukan 9 jenis CDC, yaitu: jinlai, jinqu, chulai, chuqu, xialai, xiaqu, qilai, guolai, dan shanglai. Hal ini menunjukkan tingkat keberagaman CDC yang digunakan pembelajar sudah mencapai 69\%. Namun, pembelajar tidak selalu tepat dalam menggunakan CDC di dalam kalimat. Ketidaktepatan ditemukan pada penggunaan chuqu (1), qilai (2), xialai (3), dan chulai (3). Frekuensi dan persentase dari setiap jenis CDC dapat dilihat dalam Tabel 2.

Tabel 2. Jenis dan frekuensi CDC

\begin{tabular}{|l|l|l|l|l|l|}
\hline No & Jenis CDC & $\begin{array}{c}\text { CDC } \\
\text { Arah }\end{array}$ & $\begin{array}{c}\text { CDC } \\
\text { Kiasan }\end{array}$ & Frekuensi & Persentase \\
\hline 1. & 起来 qilai & 2 & 23 & 25 & $31,25 \%$ \\
\hline 2. & 出来 chulai & 11 & 7 & 18 & $22,5 \%$ \\
\hline 3. & 下来 xialai & 7 & 7 & 14 & $17,5 \%$ \\
\hline 4. & 下去 xiaqu & 0 & 6 & 6 & $7,5 \%$ \\
\hline 5. & 过来 guolai & 6 & 0 & 6 & $7,5 \%$ \\
\hline 6. & 出去 chuqu & 5 & 0 & 5 & $6,25 \%$ \\
\hline 7. & 进去 jinqu & 4 & 0 & 4 & $5 \%$ \\
\hline 8. & 进来 jinlai & 1 & 0 & 1 & $1,25 \%$ \\
\hline 9. & 上来 shanglai & 1 & 0 & 1 & $1,25 \%$ \\
\hline Jumlah total & 37 & 43 & 80 & $100 \%$ \\
\hline
\end{tabular}

Berdasarkan tabel di atas, CDC dengan makna kiasan yang diasumsikan lebih sulit daripada CDC dengan makna arah justru lebih sering muncul dalam karangan pembelajar.

CDC dengan kemunculan terbanyak, qilai, sebagian besar digunakan untuk pemakaian kiasan dan hanya dua yang penggunaannya tidak tepat (salah pilih dan salah susun). Untuk bentuk ketidaktepatan salah pilih, pembelajar menggunakan qilai untuk kalimat yang seharusnya menggunakan chulai. Di sisi lain, pembelajar menggunakan chulai untuk kalimat yang seharusnya menggunakan qilai. Yang menarik, penukaran ini terdapat pada kalimat yang menggambarkan subjek yang mulai menangis. 
*)妈妈 不由得 恸哭了出来。

Māma bùyóude tòngkū le chulai.

*)一听她说的话, 我的眼泪一下子流了起来。

Yì tīng tā shuō de huà, $w$ de y nlèi yíxiàzi liú le quilai.

Kalimat pertama merupakan kalimat tanpa objek dan lebih menekankan pada dimulainya perbuatan tòngk $\bar{u}$ 'menangis', pembelajar seharusnya menggunakan CDC qilai. Akan tetapi, di dalam kalimat kedua terdapat verba liú 'mengalir' (termasuk ke dalam verba jenis kedua menurut Peyraube, 2006 dan Dippner, 2010). "Mengalir liû" mengakibatkan munculnya perubahan tempat dari nomina y nlèi 'air mata', yakni dari dalam kelopak mata mengalir keluar. Dengan demikian, pembelajar seharusnya memilih verba gerak chu 'keluar'.

Walaupun penggunaan CDC dengan makna kiasan lebih banyak daripada penggunaannya dengan makna arah, jenis CDC yang digunakan tidak terlalu beragam. Dari 9 jenis CDC yang telah digunakan oleh pembelajar, hampir semuanya (terkecuali jinlai dan jinqu) memiliki penggunaan kiasan. Namun, jenis CDC yang telah digunakan pembelajar untuk penggunaan kiasan hanya qilai, chulai, xialai, dan xiaqu. Berikut ini merupakan penjelasan mengenai jenis makna kiasan dari qilai, chulai, xialai, dan xiaqu yang telah digunakan oleh pembelajar.

\section{1) Qilai 起来}

Qilai dengan makna kiasan, selain frekuensi penggunaannya tinggi, tingkat ketepatannya pun tinggi (92\%). Qilai memiliki 5 makna kiasan, yaitu: mulainya suatu perbuatan, mulainya suatu perubahan keadaan, selesainya suatu perbuatan, penilaian, dan mengingat kembali (Dippner, 2010: 48-66). Lima macam makna kiasan ini dapat ditemukan dalam kalimat pembelajar.

CDC qilai dengan makna kiasan mulainya suatu perbuatan digunakan pembelajar untuk melengkapi perbuatan berteriak $(h n)$, berargumen/bertikai (zhēnglùn), tertawa (xiào), tersenyum (wéixiào), marah (shēngqi), dan menangis $(k \bar{u})$. Namun, padanan yang paling sering muncul adalah " $k \bar{u}$ " dengan "qilai" ( $k \bar{u}$ qilai) sebanyak 3 kali. Contohnya:

(10) 听到 这个消息, 我与爸爸不禁 哭起来。

Tīngdào zhè ge xiāoxi, w y bàba bùjīn kū qilai.

'Mendengar kabar ini, saya dan Ayah tak tertahankan (mulai) menangis'.

Kalimat (10) menggambarkan subjek "saya dan ayahnya" yang tidak kuasa menahan tangis. Perbuatan menangis mulai terjadi setelah mereka mendengar sebuah kabar.

Selain, qilai dengan makna mulainya suatu perbuatan, pembelajar juga banyak menggunakan CDC qilai dengan makna penilaian dan penggunaannya pun cukup beragam. Qilai dengan makna ini digunakan untuk melengkapi perbuatan lihat (kàn), 
LINGUA, Vol. 15, No. 2, September 2018

p ISSN: 1979 9411; e ISSN: 2442 238X

Http://lingua.pusatbahasa.or.id; Email:presslingua@gmail.com

Center of Language and Culture Studies, Surakarta, Indonesia

Paskalis, Bossy \& Hasanah, Nurul Hana. 2018. Ketepatan dan Variasi Penggunaan Pelengkap Arah Bahasa Mandarin dalam Karangan Pembelajar.

Lingua (2018), 15(2): 53 70. DOI: 10.30957/lingua.v15i2.477.

minum $(h \bar{e})$, menulis $(x i \check{e})$, bicara $(s h u \bar{o})$, melakukan $(z u \grave{)})$. Dari 5 perbuatan ini, qilai paling banyak muncul mendampingi kàn 'lihat' (3 kali). Contohnya:

（11）中国 的 茶看起来 和 印尼的差不多一样，不过 喝起来就 Zhōngguó de chá kàn qilai hé Yìnní de chà bu duō yíyàng, búguò hē qilai jiù 会知道 中国 的茶跟印尼的不一样。

huì zhīdào Zhōngguó de chá gên Yìnní de bù yíyàng.

'Teh Cina kelihatannya mirip dengan teh Indonesia, tetapi begitu diminum akan tahu bahwa teh Cina tidak sama dengan teh Indonesia'.

Kalimat (11) menggambarkan penilaian pembicara terhadap teh Cina. Penilaian dilakukan berdasarkan pengamatan, disampaikan melalui kan qilai dan berdasarkan pengalaman meminumnya, disampaikan melalui $h \bar{e}$ qilai. Penggunaan qilai untuk melengkapi kàn dan he sejalan dengan pendapat Zhu (dalam Dippner, 2010), bahwa pada waktu seseorang melihat, mendengar, membaui, ataupun mencicipi sesuatu, pada saat yang sama dapat memberikan penilaian terhadap sesuatu itu. Selain itu, penilaian juga dapat dilakukan berdasarkan suatu perbuatan yang telah dilakukan oleh pembicara. Hal ini ditunjukkan pembelajar melalui penggunaan xiě qilai, shuō qilai, dan zuò qilai.

Penggunaan CDC qilai dengan makna kiasan mengingat kembali hanya untuk melengkapi verba tertentu, antara lain: $x i$ ng 'ingat', huíyi 'mengenang', jìde 'teringat' (Dippner, 2010:64-66). Pada data ditemukan 5 penggunaan qilai dengan makna kiasan ini, tetapi hanya untuk melengkapi $x i n g$.

(12) 我突然想 起来 我幼儿园 时 参加的一 场 比赛。 $W$ túrán xiăng qilai w yòu'éryuán shí cānjiā de yì ch ng b sài.

'Saya tiba-tiba teringat suatu pertandingan yang saya ikuti ketika masih di taman kanak-kanak.'

(13) 妈妈忽然 想 起来, 她把几把钥匙 放 在 她的 口袋 里了,[...]。 Māma hūrán xiăng $q$ lái, $t a \bar{a} b \quad j \quad b$ yàoshi fàng zài tā de $k$ udài li le, [...]. 'Ibu tiba-tiba teringat, dia menaruh beberapa kunci di sakunya, [...].'

CDC qilai dengan makna mengingat kembali yang ditemukan dalam kalimat pembelajar tidak terbatas untuk mengingat kembali suatu peristiwa yang sudah lama berlalu (kalimat 12), tetapi juga untuk mengingat kembali suatu hal yang sempat terlupakan sesaat (kalimat 13).

Selanjutnya, ditemukan juga penggunaan CDC qilai bermakna kiasan mulainya suatu perubahan keadaan yang terdapat dalam kalimat berikut:

(14) 初次, 我觉得这只是一时的情况, 慢慢 会好起来。 Chūcì, $w$ juéde zhè zh shì yìshí de qíngkuàng, mànman huì hăoqilai.

'Untuk pertama kalinya, saya pikir ini hanya situasi sementara, perlahan-lahan akan membaik.' 
Qilai dengan makna ini hanya muncul melengkapi adjektiva dan perubahan terjadi secara instan (Dippner, 2010:51-52). Di dalam kalimat (14) qilai berada di belakang $h o$ 'baik'. Situasi yang dialami subjek "w 'saya" akan membaik ( $h$ o qilai), tetapi perubahan keadaan dari kurang baik menjadi baik ini berlangsung secara perlahan-lahan (mànman). Penggunaan qilai dengan makna kiasan seperti ini hanya muncul 1 kali.

Selain itu, yang muncul hanya satu kali juga adalah penggunaan qilai dengan makna selesainya suatu perbuatan. Dalam hal ini, qilai digunakan di belakang "momentary verbs" (Dippner, 2010). Makna selesainya suatu perbuatan pada dasarnya melibatkan aktivitas menyembunyikan atau menutup sesuatu sehingga tidak terlihat oleh orang lain, menyusun/merapihkan sesuatu agar terkumpul menjadi satu, misalnya membungkus 'bao qilai' (Universitas Peking, 1981:196; Dippner, 2010:57-59). Di dalam kalimat pembelajar, qilai digunakan untuk melengkapi perbuatan cáng 'menyembunyikan'.

\section{(15) 我 把 我所有 的 感觉 藏起来, 免得 我们 的情义 变 坏了。 $W \quad b \quad w$ su y u de g njué cáng qilai, mi ndé w men de qíngyì biàn huài le. 'Saya menyembunyikan semua perasaan saya, agar pertemanan kami tidak memburuk.'}

\section{2) Chulai 出来}

Menurut Dippner CDC chulai memiliki 3 macam makna kiasan, yaitu: mengenali seseorang atau sesuatu, kemunculan (dari tidak ada menjadi ada), dan ketakterdugaan. Namun yang ditemukan dalam kalimat pembelajar hanya makna kemunculan (emergence). Pembelajar selain baru bisa menggunakan satu makna kiasan dari chulai, verba yang mendampinginya pun juga selalu sama, yaitu shuō. Shuō qilai muncul sebanyak 5 kali dalam karangan pembelajar, salah satu contohnya adalah sebagai berikut:

(16) 我自信地回答把所有 的看法 说 出来。

$W$ zìxìn de huídá b su y u de kànf shuō chulai.

'Saya menjawab dengan yakin dan mengemukakan semua pendapat saya.'

\section{3) Xialai 下来}

Xialai memiliki makna kiasan selesainya suatu perbuatan, perubahan situasi secara perlahan-lahan (khusus melengkapi adjektiva), dan hirarki (Dippner, 2010). Namun, sama halnya dengan chulai, hanya satu macam makna kiasan yang muncul dalam kalimat pembelajar, yaitu selesainya suatu perbuatan. Hal yang membedakannya dengan penggunaan chulai adalah ragam perbuatan yang dilengkapinya berbeda-beda. Pembelajar menggunakan chulai untuk melengkapi:

- aktivitas: “menulis xiě 写”, contohnya:

(17) 我 奶奶在 墙 上也把打起 精神 的句子写下来。 $W n$ inai zài qiáng shàng yě $b \quad d \quad q$ jīngshén de jùzi xiěxialai. 
LINGUA, Vol. 15, No. 2, September 2018

p ISSN: 1979 9411; e ISSN: 2442 238X

Http://lingua.pusatbahasa.or.id; Email:presslingua@gmail.com

Center of Language and Culture Studies, Surakarta, Indonesia

Paskalis, Bossy \& Hasanah, Nurul Hana. 2018. Ketepatan dan Variasi Penggunaan Pelengkap Arah Bahasa Mandarin dalam Karangan Pembelajar. Lingua (2018), 15(2): 53 70. DOI: 10.30957/lingua.v15i2.477.

'Nenek saya juga menulis kalimat yang membangkitkan semangat itu di dinding.'

- perbuatan yang berkaitan dengan menyimpan/mendokumentasikan suatu informasi: "memotret $p \bar{a} i$ 拍”, contohnya:

(18) 第二 张 是我七 年 前 跟家人 拍下来的。

Dì èr zhāng shì w qū nián qián gēn jiārén päi xialai de.

'Lembar kedua adalah foto yang diambil bersama keluarga saya tujuh tahun lalu.'

- perbuatan yang yang telah mencapai akhir: “memutuskan juéding 决定 dan “menyimpulkan $z$ ngjié 总结”, contohnya:

(19) 我也总结下来了, 自信就是 成功 首要 条件。

W yě zơngiéxiàlái le, zìxìn jiùshì chénggōng sh uyào tiáojiàn.

'Saya pun sudah menyimpulkan, kepercayaan diri adalah syarat utama untuk sukses.'

Secara teoretis xialai dengan makna selesainya suatu perbuatan juga dapat melengkapi perbuatan yang berkaitan dengan memisahkan/mencopotkan/melepaskan suatu barang/objek dan melestarikan sesuatu dari waktu ke waktu (Dippner, 2010:3940). Akan tetapi, dua ragam makna yang terakhir ini belum muncul dalam kalimat pembelajar.

\section{4) Xiaqu下去}

Frekuensi penggunaan xiaqu dalam karangan pembelajar tidak terlalu banyak, hanya muncul 6 kali dan yang menarik semuanya digunakan untuk pemakaian kiasan. Xiaqu sebagai CDC hanya memiliki dua macam makna kiasan, yaitu kelanjutan perbuatan dan hirarki (Dippner, 2010). Namun, pembelajar baru dapat menggunakan xiaqu untuk menyatakan makna "kelanjutan perbuatan" (continuation of action). Penggunaan dengan makna kiasan seperti ini muncul melengkapi perbuatan "belajar xué 学”, “berlatih liànxí 练习”, “berjalan $z u$ 走”, dan “menyimpan b ocún 保存”, contohnya:

\section{(20) 哪怕是那张生日卡和所有 照片 都 变黄, 他 仍然 $N$ pà shì nàzhāng shēngrì $k$ hé su y u zhàopiàn dōu biàn huáng, tā réngrán 要坚持 把 它细心地 保存下去。 yào jiānchí b tā xìxīn de băoán xiaqu.}

'Sekalipun kartu ulang tahun itu dan semua foto menjadi kuning, dia masih tetap akan menyimpannya dengan hati-hati.'

Pada kalimat (20) penggunaan CDC xiaqu terdapat pada anak kalimat kedua. Di dalamnya digambarkan subjek "dia $t \vec{a}$ " selama ini menyimpan kartu ucapan serta fotofoto ulang tahun dan masih akan terus menyimpannya ( $b$ ocún xiaqu). 
LINGUA, Vol. 15, No. 2, September 2018

p ISSN: 1979 9411; e ISSN: 2442 238X

Http://lingua.pusatbahasa.or.id; Email:presslingua@gmail.com

Center of Language and Culture Studies, Surakarta, Indonesia

Paskalis, Bossy \& Hasanah, Nurul Hana. 2018. Ketepatan dan Variasi Penggunaan

Pelengkap Arah Bahasa Mandarin dalam Karangan Pembelajar.

Lingua (2018), 15(2): 53 70. DOI: 10.30957/lingua.v15i2.477

\section{SIMPULAN}

Ada tiga hal utama yang perlu diperhatikan dalam penggunaan pelengkap arah, yakni: hubungan antara titik acuan dengan arah perbuatan, susunan kalimat berpelengkap arah (terkait dengan kehadiran objek, keterangan tempat, partikel le), dan arah gerak perbuatan (khusus untuk CDC). Berdasarkan $87.8 \%$ data dengan penggunaan pelengkap arah yang tepat, penulis menemukan bahwa ketepatan pembelajar telah mencakup tiga hal utama itu.

Sebagaimana yang telah diasumsikan, letak ketidaktepatan pelengkap arah bermakna penunjuk arah (harfiah) tidak sama dengan pelengkap arah bermakna kiasan. Dalam penggunaan pelengkap arah bermakna harfiah, bentuk SDC maupun CDC, ketidaktepatan terletak pada penentuan arah perbuatan dengan titik acuan. Hal ini terutama ditemukan dalam kalimat yang menggambarkan perbuatan menjauhi titik acuan (posisi pembicara).

Sementara itu, letak ketidaktepatan CDC bermakna kiasan terkait dengan susunan dan pemilihan verba gerak. Penempatan verba gerak dan verba penunjuk arah terkadang tidak tepat apabila ada objek dari suatu perbuatan yang telah dilakukan. Selain itu, pembelajar beberapa kali tertukar antara penggunaan qi dan chu. Pembelajar menggunakan CDC qilai untuk kalimat yang seharusnya menggunakan CDC chulai dan begitu juga sebaliknya.

Satu hal yang menarik dalam sistem antarbahasa pembelajar tingkat menengah ${ }^{7}$ adalah urutan penguasaan CDC. Dalam data terdapat $88.9 \%$ penggunaan CDC, bahkan lebih dari 50\% CDC yang digunakan adalah yang bermakna kiasan dan tingkat ketepatan tertinggi terdapat dalam penggunaan CDC qilai bermakna kiasan. Dapat disimpulkan salah satu jenis CDC kiasan dikuasai lebih dulu daripada CDC bermakna arah yang manapun.

Tingkat ketepatan penggunaan pelengkap arah Bahasa Mandarin oleh pembelajar yang sudah cukup tinggi ini, menunjukkan performa pembelajar di tingkat menengah sudah baik. Namun, keberagaman penggunaan CDC bermakna kiasan merupakan satu aspek yang masih perlu dilatih lebih lanjut.

\section{DAFTAR PUSTAKA}

Cakradiwati, Ayubi dan Hasanah, Hana Nurul. 2017. "Pelengkap Arah Majemuk 起来 $Q$ lái dan 出来 Chūlái: Perbedaan dalam Distribusi dan Pemakaiannya dalam Kalimat", dalam: Proceeding of the International Young Scholars Symposium on Humanities and Arts 2017: 38-54. Tersedia pada: https://inusharts.ui.ac.id/wpcontent/uploads/sites/31/2018/01/Proceeding_INUSHARTS17_FINAL-2018 JAN24.pdf.

Dippner, Kevin. 2010. Metaphorical Use of Mandarin Compound Directional Complements. Oslo: Oslo University.

\footnotetext{
${ }^{7}$ Mahasiswa peserta mata kuliah BC V dan BC VI Program Studi Cina UI.
} 
Hui Yin. 2011. "The Cognitive Semantics of Chinese Motion/Directional Verbs", Working Papers of the Linguistics Circle of the University of Victoria 21:118125. Tersedia pada: https://journals.uvic.ca/index.php/WPLC/article/ view/5945/2701.

James, Carl. 1998. Errors in Language Learning and Use. Malaysia: Longman.

Li Dejin dan Cheng Meizhen. 2008. A Practical Chinese Grammar for Foreigners. Beijing Language and Culture University Press. Tersedia pada: http://vdisk.weibo.com/s/sJweghc XH5Ic.

Li Yan. 2016. "A Study on the Second Language Acquisition for Chinese Simple Directional Complement" dalam Sino-US English Teaching, 13 (11): 885-896. Tersedia pada: https://www.davidpublisher.org/Public/uploads/Contribute/ 582aa74166ff3.pdf.

Liu Yuehua, Pan Wenyu, dan Gu Wei. 2003. 实用现代汉语语法 Shíyòng xiàndài Hàny y $f$. Beijing: Commercial Press.

Peyraube, Alain. 2006. "Motion Events in Chinese: A Diachronic Study of Directional Complements". Tersedia pada: https://www.researchgate.net/publication/29079 3924_Motion_events_in_Chinese_a_diachronic_study_of_directional_compleme nts.

Qi, Chunhong, Panpan Zhao, dan Wei Na. 2016. "Suggestions on Teaching Chinese Directional Complements Based on Chinese Typological Characteristics". Prosiding dalam 2nd International Conference on Education Science and Human Development (ESHD 2016). Tersedia pada: http://dpi-proceedings.com/ index.php/dtssehs/article/view/ 5193/4817.

Roose, Kristin. 2010. Using the Simple and Complex Directional Complements in Chinese for Beginners. Muncie, IN: Ball State University. Tersedia pada: https://cardinalscholar.bsu.edu/bitstream/handle/handle/192280/R66_2010Roose Kristin.pdf? sequence $=1$ \&isAllowed $=\mathrm{y}$.

Universitas Peking. 1981. Modern Chinese: A Second Course. New York: Dover Publication.

Yang Jizhou et al. 2013. Hanyu Jiaocheng, Buku Mandarin Komprehensif Volume 3 (cetakan Indonesia). Jakarta: Legacy. 